\title{
HETEROSPECIFIC FORAGING ASSOCIATIONS BETWEEN REEF-ASSOCIATED SHARKS: FIRST EVIDENCE OF KLEPTOPARASITISM IN SHARKS
}

\author{
Pierre Labourgade, Laurent Ballesta, Charlie Huveneers (iD, \\ Yannis Papastamatiou (D), and Johann Mourier (iD
}

\section{Study Description}

Social predation allows groups of predators to search for, pursue, and capture prey with greater efficiency than using solitary hunting. During $\sim 3,000$ hours of underwater observations of nocturnal shark foraging activity, we report for the first time a heterospecific association between two shark species, with the nature of the interaction ranging from commensalism to kleptoparasitism and mutualism. These foraging associations with whitetip reef sharks offer grey reef sharks the opportunity to access different types of prey and increase their predation success. These findings add more evidence that heterospecific social associations may exist across animal groups including large marine predators.

Labourgade, P., L. Ballesta, C. Huveneers, Y. Papastamatiou, and J. Mourier. 2020. Heterospecific Foraging Associations Between Reef-Associated Sharks: First Evidence of Kleptoparasitism in Sharks. Bull Ecol Soc Am 101(4):e01755. https://doi.org/10.1002/bes2.1755 


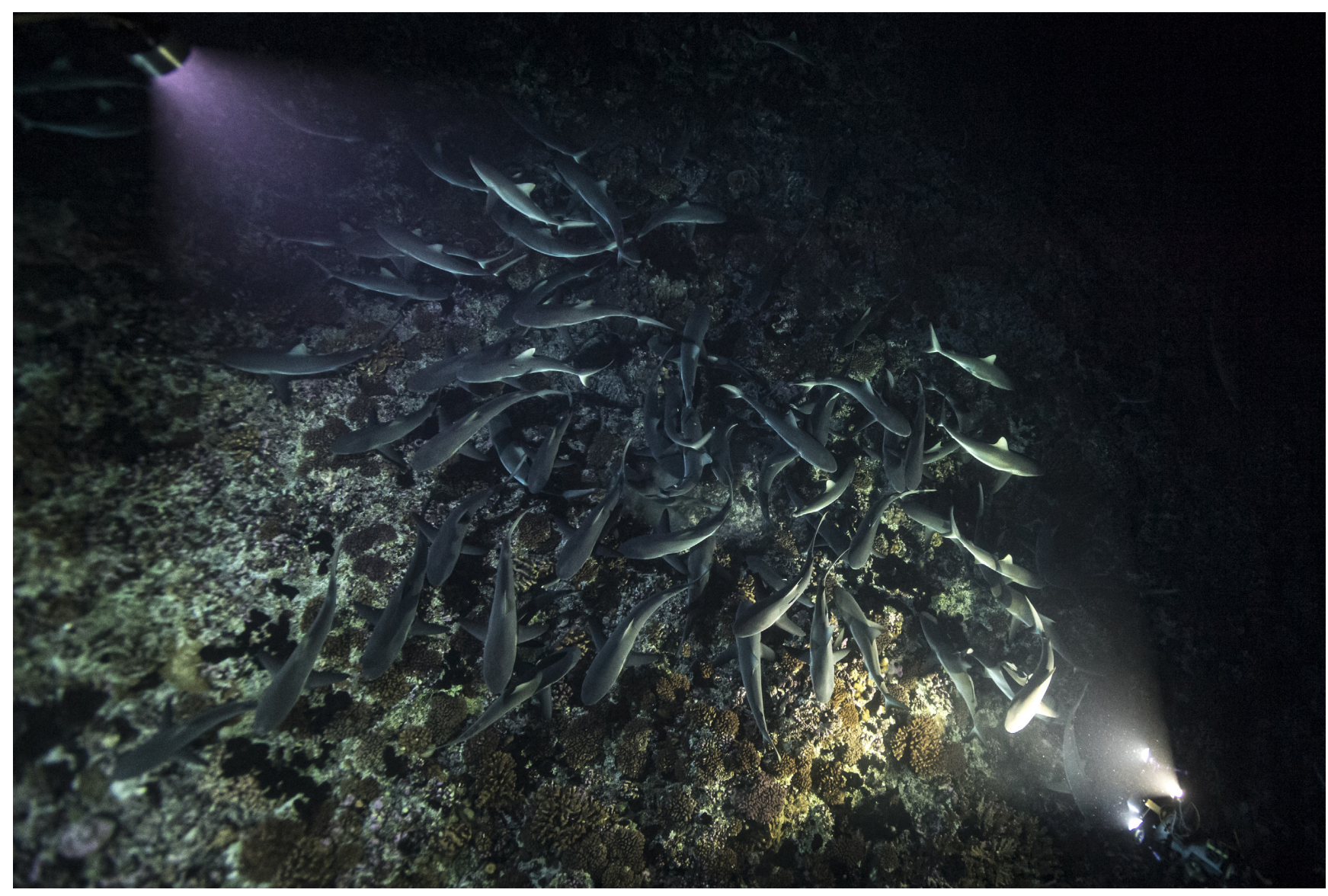

Photo I. Our team documented the nocturnal foraging activity of reef sharks in the south channel of the Fakarava atoll in French Polynesia. This atoll hosts a shark population of $\sim 900$ resident reef sharks that use it to rest during the day and hunt reef fish at night. Photo credit goes to Laurent Ballesta. 


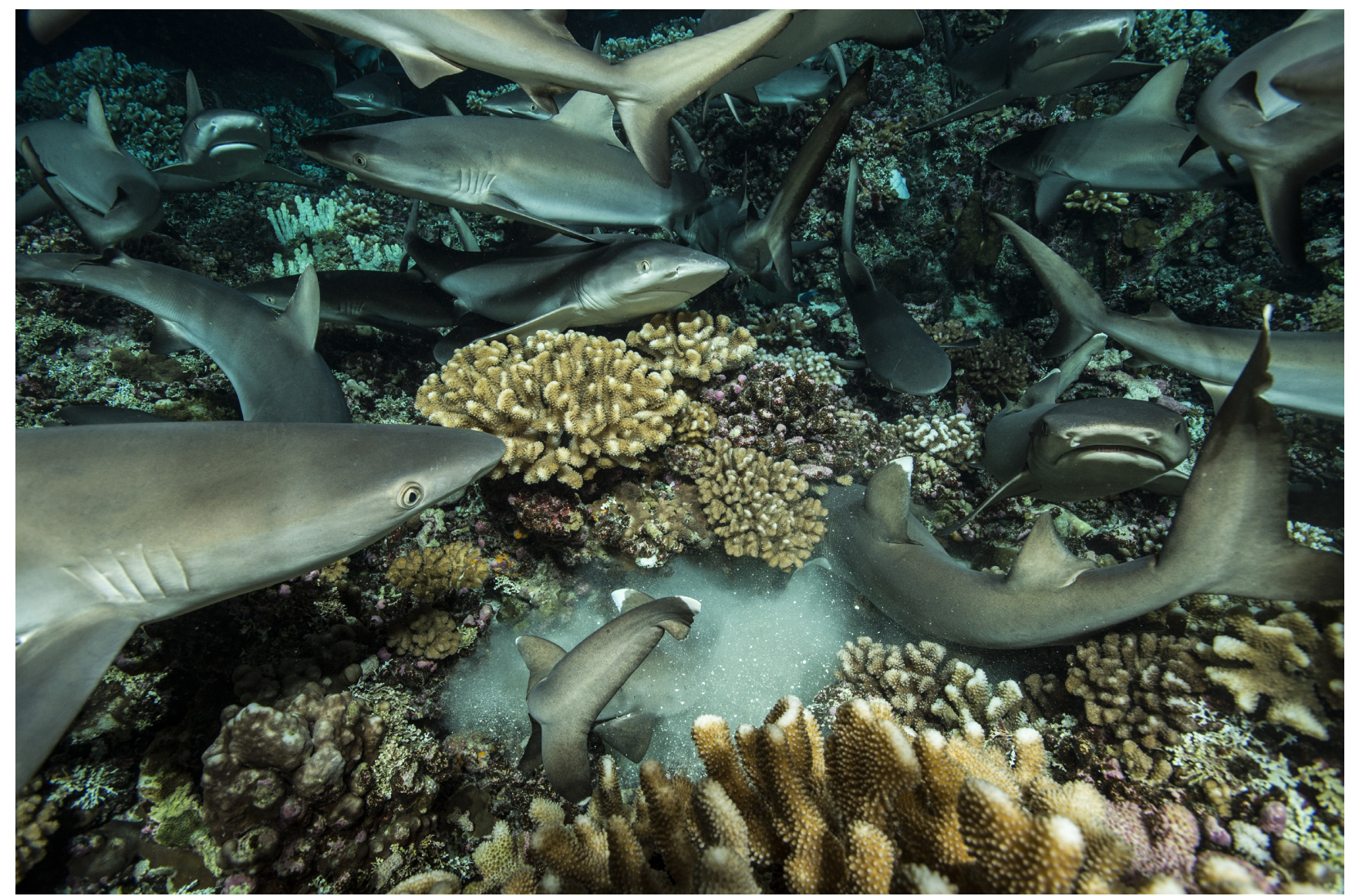

Photo 2. Whitetip reef sharks (Triaenodon obesus), which are recognizable by the white tips at the extremity of their fins, have a flexible body which allow them to get deeper into holes and crevices of the reef to catch hidden prey. Grey reef sharks (Carcharhinus amblyrhynchos) are unable to do so and instead wait for whitetip reef sharks to disturb fish from their hiding places. Photo credit goes to Laurent Ballesta. 


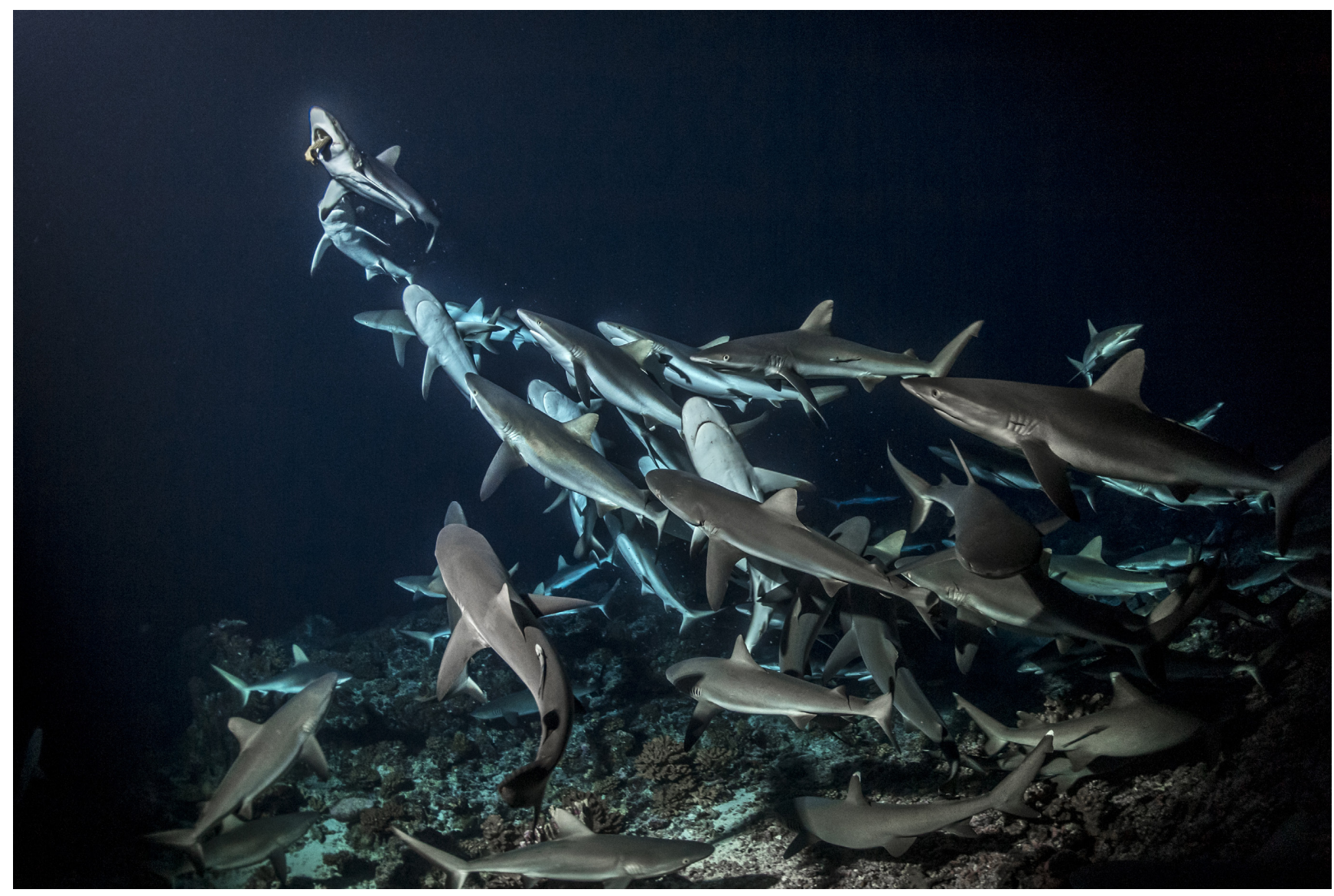

Photo 3. This type of predation is particularly beneficial to the grey reef shark that exploits the assets of another species, which increases their predatory success rate. While this association does not affect whitetip reef sharks predatory success in most cases, grey reefs sharks can steal the prey from its nuclear associate, shifting the relationship from mutualism to kleptoparasitism. Photo credit goes to Laurent Ballesta.

These photographs illustrate the article "Heterospecific foraging associations between reefassociated sharks: first evidence of kleptoparasitism in sharks” by Pierre Labourgade, Laurent Ballesta, Charlie Huveneers, Yannis Papastamatiou, and Johann Mourier published in Ecology. https://doi.org/10.1002/ecy.3117. 